Article

\title{
Tuning Mesenchymal Stem Cell Response onto Titanium- Niobium-Hafnium Alloy by Recombinant Fibronectin Fragments
}

Carolina Herranz-Diez, Carlos Mas-Moruno, Stefanie Neubauer, Horst Kessler, Francisco Javier Gil, Marta Pegueroles, José Maria Manero, and Jordi Guillem-Marti

ACS Appl. Mater. Interfaces, Just Accepted Manuscript • DOI: 10.1021/acsami.5b09576 • Publication Date (Web): 06 Jan 2016

Downloaded from http://pubs.acs.org on January 7, 2016

\section{Just Accepted}

"Just Accepted" manuscripts have been peer-reviewed and accepted for publication. They are posted online prior to technical editing, formatting for publication and author proofing. The American Chemical Society provides "Just Accepted" as a free service to the research community to expedite the dissemination of scientific material as soon as possible after acceptance. "Just Accepted" manuscripts appear in full in PDF format accompanied by an HTML abstract. "Just Accepted" manuscripts have been fully peer reviewed, but should not be considered the official version of record. They are accessible to all readers and citable by the Digital Object Identifier (DOI®). "Just Accepted" is an optional service offered to authors. Therefore, the "Just Accepted" Web site may not include all articles that will be published in the journal. After a manuscript is technically edited and formatted, it will be removed from the "Just Accepted" Web site and published as an ASAP article. Note that technical editing may introduce minor changes to the manuscript text and/or graphics which could affect content, and all legal disclaimers and ethical guidelines that apply to the journal pertain. ACS cannot be held responsible for errors or consequences arising from the use of information contained in these "Just Accepted" manuscripts. 


\title{
Tuning Mesenchymal Stem Cell Response onto Titanium-Niobium-Hafnium Alloy by Recombinant Fibronectin Fragments
}
C. Herranz-Diez ${ }^{\mathrm{a}, 1}$, C. Mas-Moruno ${ }^{\mathrm{a}, \mathrm{b}}$, S. Neubauer ${ }^{\mathrm{c}, \mathrm{d}}$, H. Kessler, ${ }^{\mathrm{c}, \mathrm{d}}$, F.J. Gil ${ }^{\mathrm{a}, \mathrm{b}}$, M. Pegueroles $^{\mathrm{a}, \mathrm{b}}$, J.M. Manero ${ }^{\mathrm{a}, \mathrm{b}}$, J. Guillem-Marti ${ }^{\mathrm{a}, \mathrm{b}^{*}}$

${ }^{\mathrm{a}}$ Biomaterials, Biomechanics and Tissue Engineering Group, Department of Materials Science and Metallurgical Engineering, Technical University of Catalonia (UPC), ETSEIB, Diagonal 647, 08028 Barcelona, Spain.

${ }^{\mathrm{b}}$ Centre for Research in NanoEngineering (CRnE)-UPC, c/Pascual i Vila 15, 08028 Barcelona, Spain

c Institute for Advanced Study and Center for Integrated Protein Science, Department Chemie, Technische Universität München, Lichtenbergstr. 4, 85747 Garching, Germany.

\author{
${ }^{\mathrm{d}}$ Max Planck Institute for Intelligent Systems, Heisenbergstr. 3, 70569 Stuttgart, Germany \\ *Corresponding author: Dr. J. Guillem-Marti: Biomaterials, Biomechanics and Tissue \\ Engineering Group, Department of Materials Science and Metallurgy, Technical University \\ of Catalonia (UPC), ETSEIB, Av. Diagonal 647, 08028 Barcelona, Spain. \\ E-mail address: jordi.guillem.marti@upc.edu \\ 1. Present address: Academic Unit of Restorative Dentistry, School of Clinical Dentistry, \\ University of Sheffield, Claremont Crescent, Sheffield S10 2TA, UK.
}




\begin{abstract}
Since metallic biomaterials used for bone replacement possess low bioactivity, the use of cell adhesive moieties is a common strategy to improve cellular response onto these surfaces. In recent years the use of recombinant proteins has emerged as an alternative to native proteins and short peptides owing to the fact that they retain the biological potency of native proteins, while improving their stability. In the present study, we investigated the biological effect of two different recombinant fragments of fibronectin, spanning the $8^{\text {th }}-10^{\text {th }}$ and $12^{\text {th }}-14^{\text {th }}$ type III repeats, covalently attached to a new TiNbHf alloy using APTES silanization. The fragments were studied separately and mixed at different concentrations and compared to a linear RGD, a cyclic RGD and the full-length fibronectin protein. Cell culture studies using rat mesenchymal stem cells demonstrated that low to medium concentrations $(30 \%$ and $50 \%)$ of type III $8^{\text {th }}-10^{\text {th }}$ fragment mixed with type III $12^{\text {th }}-14^{\text {th }}$ fragment stimulated cell adhesion and proliferation compared to RGD peptides and the fragments separately. On the other hand, type III $12^{\text {th }}-14^{\text {th }}$ fragment alone or mixed at low volume percentages $\leq 50 \%$ with type III $8^{\text {th- }}$ $10^{\text {th }}$ fragment increased alkaline phosphatase levels compared to the other molecules. These results are significant for the understanding of the role of fibronectin recombinant fragments in cell responses and thus to design bioactive coatings for biomedical applications.
\end{abstract}

KEYWORDS: Fibronectin; recombinant protein; cell adhesive peptides; mesenchymal stem cells; titanium alloy 


\section{INTRODUCTION}

Titanium (Ti) and Ti-based alloys have been traditionally used for bone implantation purposes. ${ }^{1}$ Despite the good biocompatible properties showed by these materials, there is a mismatch with bone elastic modulus, which is translated in a stress shielding effect. ${ }^{2}$ In a bone replacement scenario, the prosthesis shares the load and carrying capacity of bone. The loads applied to bone are reduced leading to a new loads distribution and eventually to bone resorption, which is a major cause of implant failure. Ductile metals such as $\mathrm{Zr}$, Ta, $\mathrm{Nb}$ or $\mathrm{Hf}$ are used to stabilize the beta phase in Ti-alloys, ${ }^{3-5}$ which is the phase with lowest elastic modulus, and also because they possess osseoinductive properties. ${ }^{6}$ A particularly interesting Ti-based alloy is the TiNbHf ternary system. This system has shown interesting properties such as low elastic modulus, good biocompatibility and no cytotoxic effects. ${ }^{7,8}$ In this regard, we have recently developed the Ti25Nb21Hf alloy, which exhibited lower elastic modulus and higher wear resistance compared to $\mathrm{Ti}^{9}$

Despite the interesting biocompatibility and mechanical properties exhibited by TiNbHf alloys, these metallic biomaterials are not bioactive and thus do not promote osseointegration at an optimal rate, compromising in some circumstances the long-lasting stability of the implants. For this reason, in recent years several efforts have concentrated on the biofunctionalization of the biomaterials surface to improve their bioactivity and hence their osseointegration. ${ }^{10}$ In detail, the main goal of biofunctionalization is to generate an extracellular matrix (ECM)-like environment that positively influences the behaviour of osteoblast and bone precursors (i.e. mesenchymal stem cells, MSCs) and effectively guides bone growth. ${ }^{11,12}$ The ideal strategy is the use of native bone ECM proteins, such as collagen or fibronectin (FN), for coating the surfaces. ${ }^{13,14}$

However, although these proteins retain their full biological functionality and specificity, they display low stability after functionalization along with many other drawbacks including 
high production costs and immunogenicity, which have reduced their biomedical potential. ${ }^{11}$ The use of ECM-derived synthetic peptides containing the functional sites of ECM proteins is an interesting approach to overcome these problems. ${ }^{10,11}$ The advantages of these motives in regards to ECM proteins are their higher stability, lower production costs and their capability to be synthetically tailored in composition for specific biological applications.

In particular, integrin-binding sequences are of great interest since they regulate not only cell adhesion but also cell survival, proliferation and differentiation. This is illustrated by the cell adhesive arginine-glycine-aspartic acid (RGD) motif, which is present in many ECM proteins including FN, vitronectin, bone sialoprotein and osteopontin, and has been widely used to mimic cell/matrix interactions and improve the osteointegration of implant materials. ${ }^{10-12,15}$

Nonetheless, short synthetic peptides are commonly less functional and specific than fulllength proteins due to the absence of complementary domains required for biological activity or inadequate conformation, both of which are crucial to trigger an appropriate cell response. ${ }^{16}$ To solve these problems, different approaches aiming at improving the activity and selectivity profile of integrin ligands have been followed: cyclic peptides, ${ }^{17-19}$ peptidomimetics, ${ }^{20-23}$ mixtures of peptides ${ }^{24-26}$ or peptide-based platforms. ${ }^{27}$

The use of recombinant protein fragments for functionalizing surfaces has emerged as a potential strategy that combines the benefits of the aforementioned methods. ${ }^{28-31}$ Using recombinant DNA technology the signalling domain of an ECM protein can be engineered to retain crucial biological features such as the conformation and spacing of bioactive sequences, while reducing the antigenicity and improving the stability of native proteins. Noteworthy, fusion of more than one domain from the same protein or domains from different proteins can be assembled modulating different cell responses with only one molecule. ${ }^{32-34}$ 
FN is a well-known ECM protein that mediates many cellular processes like cell adhesion, migration, growth and differentiation. ${ }^{35} \mathrm{FN}$ contains a region involved in cell adhesion located in the type $\mathrm{III}_{10}$ domain, which includes the above-mentioned RGD sequence. In addition, the type $\mathrm{III}_{9}$ domain contains the PHSRN (Pro-His-Ser-Arg-Asp) sequence, which strongly modulates and increases the binding affinity of RGD to $\alpha 5 \beta 1$ integrin. ${ }^{35,36}$

Previous studies have demonstrated that the cell attachment site (CAS) recombinant fragment of $\mathrm{FN}$, consisting of type $\mathrm{III}_{8-10}$ repeats or $\mathrm{III}_{7-10}$ enhances cell adhesion, proliferation and differentiation. ${ }^{28,37}$ Studies by Martino et al. $^{31}$ demonstrated the good adhesion and osseoinduction potential of MSCs in contact with the FNIII $_{9-10}$ fragment. Petrie et al. ${ }^{30}$ showed the capacity of the $\mathrm{FN} \mathrm{III}_{7-10}$ fragment to increase osteoblastic differentiation and mineralization in vitro and enhanced implant osseointegration in a rat cortical bone model compared to RGD and fibronectin. In vivo studies by Agarwal et al. demonstrated that the FN $\mathrm{III}_{7-10}$ fragment promotes $\alpha_{5} \beta_{1}$ integrin-dependent adhesion and osteogenic differentiation of hMSCs. $^{38}$

Besides the CAS, there is another region in $\mathrm{FN}$, the C-terminal type $\mathrm{III}_{12-14}$ heparin-binding II (HBII) domain also crucially involved in cytoskeletal organization and focal adhesion formation. This HBII domain binds to proteoglycans, including heparan sulfate proteoglycans (HSPGs) such as syndecans. ${ }^{39}$ For instance, syndecan-4 has been described to play an important role in the regulation of the activation of several integrins through the HBII domain. ${ }^{40}$ Moreover, it has been shown that HB domains in FN enhance cell adhesion and proliferation of osteoblasts together with the CAS domain. ${ }^{39}$ Another important feature of the HBII domain was described by Martino et al. ${ }^{41}$ In his studies, its capability to sequester growth factors from different families was demonstrated.

The present work aims to covalently functionalize a Ti25Nb21Hf alloy with FNIII ${ }_{8-10}$ and FNIII ${ }_{12-14}$ recombinant fragments alone or combined at different concentrations to elucidate 
the importance of each fragment on the biological response for implant applications. These sequences have been compared to FN and two short synthetic RGD peptides (linear and cyclic, linRGD and cRGD, respectively). Cellular behaviour has been analysed in terms of cell adhesion, proliferation and differentiation using rat mesenchymal stem cells (rMSCs).

\section{MATERIALS AND METHODS}

\subsection{TiNbHf alloy fabrication and preparation}

The alloy was fabricated as described in ${ }^{9}$. Briefly, commercially pure (CP)-Ti, $\mathrm{Nb}(99.8 \%$ purity) and Hf (99.7\% purity) were arc melted and vacuum homogenized. Bars of diameter $10 \mathrm{~mm}$ were obtained by extrusion. TiNbHf alloy bars were cut in discs of $2 \mathrm{~mm}$ thickness and grinded with SiC papers of grit 320, 800, 1200 and 2500 (Struers, Spain). After grinding, the discs were mirror polished with colloidal silica (size particle $0.05 \mu \mathrm{m}$, ATM GmbH, Germany). Samples were cleaned in an ultrasound bath with cyclohexane, isopropanol, ethanol, deionized water and acetone (all chemicals were of the highest purity available from Sigma-Aldrich, USA).

\subsection{Recombinant FN fragments}

Recombinant DNA techniques were used to synthetize two different fragments of human FN: i) the Cell Attachment Site (CAS) sequence, spanning the 8th-10th type III repeats, and ii) the Heparin Binding II (HBII) sequence spanning the 12th-14th type III repeats. DNA extracted from SaOS-2 cells was specifically amplified by PCR using 5'GTCGACAAGTTCCTCCTCCCACTGACCT-3' ${ }^{\prime}$ and GCGGCCGCTtAATGGAAATtGGCTTGCTG-3' (for CAS domain) or 5'GTCGACAAGCTATTCCTGCACCAACTGA-3' 5' GCGGCCGCTGTCTTTTTCCTTCCAATCAGG-3' (for HBII domain). Each DNA fragment was digested with SalI and NotI (New England Biolabs, USA) and ligated into a pGEX-6P-1 
plasmid (GE Healthcare, UK). The resulting constructs, containing CAS or HBII with a glutathione S-transferase (GST) tagging sequence at the amine terminus, were separately amplified in DH5 $\alpha$ cells (Invitrogen, USA), purified and sequenced. Then, BL21 E.coli strains (Invitrogen) were separately transformed with the plasmids and streaked onto LB agar plates containing $100 \mu \mathrm{g} / \mathrm{ml}$ of ampicillin and incubated at $37^{\circ} \mathrm{C}$ overnight. Colonies were isolated and dynamically cultured in LB broth (Sigma-Aldrich) with $100 \mu \mathrm{g} / \mathrm{ml}$ of ampicillin at $37^{\circ} \mathrm{C}$ until they reached an $\mathrm{OD}_{600}=0.6$. Expression of the fragments was induced by addition of $1 \mathrm{mM}$ IPTG. After $4 \mathrm{~h}$, cells were harvested by centrifugation and lysed by sonication. Then, $20 \%$ Triton $\mathrm{X}-100$ was added and the suspension was incubated at $4{ }^{\circ} \mathrm{C}$ for 30 min under mild agitation. The suspension was then centrifuged and the supernatant was purified at $4{ }^{\circ} \mathrm{C}$ using GSTrap affinity columns (GE Healthcare) in an ÄKTA purifier (GE Healthcare). GST tag was on-column removed by cleavage with HRV3C Protease (SigmaAldrich) in Cleavage Buffer (50 mM Tris-HCl, $150 \mathrm{mM} \mathrm{NaCl}, 1 \mathrm{mM}$ EDTA, $1 \mathrm{mM}$ dithiothreitol, $\mathrm{pH}$ 7.0). Purity was verified to be $>95 \%$ by SDS-PAGE. Protein concentrations were determined by BCA assay (Pierce, Thermo Fisher Scientific, USA).

\subsection{Synthesis of linear RGD peptide (linRGD)}

The linear peptide MPA-Ahx-Ahx-Ahx-Gly-Arg-Gly-Asp-Ser-OH (linRGD) (Ahx: aminohexanoic acid; MPA: 3-mercaptopropionic acid) was manually synthesized by solidphase peptide synthesis (SPPS) following the Fmoc/tBu strategy ${ }^{42}$ and using 2-chlorotrityl chloride resin (CTC, $200 \mathrm{mg}, 1.6 \mathrm{mmol} / \mathrm{g}$ ) (Iris Biotech $\mathrm{GmbH}$, Germany) as solid support. Fmoc-L-amino acids were obtained from Iris Biotech $\mathrm{GmbH}$ and coupling reagents from Sigma-Aldrich and Luxembourg Industries Ltd. (Israel). All other chemicals and solvents were acquired from Sigma-Aldrich, Alfa Aesar (Germany) and SDS (France). The first amino acid was incorporated by sequential addition of Fmoc-Ser(tBu)-OH (1 equiv) and N,Ndiisopropylethylamine (DIEA) (10 equiv). After $1 \mathrm{~h}$ under stirring the resin was capped with 
$\mathrm{MeOH}(0.8 \mathrm{~mL} / \mathrm{g}$ of resin). The Fmoc group was removed by treatment with piperidine/N,Ndimethylformamide (DMF) $(1: 4, \mathrm{v} / \mathrm{v})$ and the following coupling reactions were carried out with Fmoc-L-amino acids (4 equiv), Oxyma Pure $(4$ equiv) and N,N'diisopropylcarbodiimide (DIC) (4 equiv) in DMF for $45 \mathrm{~min}$. The efficiency of each reaction was monitored using the Kaiser test and by analytical HPLC analysis (Waters Alliance 2695 chromatography system) (Waters, USA). After synthesis, the peptide was cleaved from the solid support with concomitant deprotection of the side chain protecting groups. To this end, the resin was washed with dichloromethane (DCM), dried, and treated with trifluoroacetic acid (TFA) $/ \mathrm{H}_{2} \mathrm{O} /$ triisopropylsilane (TIS) $(95: 2.5: 2.5)$ for $1.5 \mathrm{~h}$. The peptide was then precipitated with cold diethyl ether, centrifuged and washed twice with diethyl ether. This crude peptide was dissolved in $\mathrm{H}_{2} \mathrm{O} / \mathrm{MeCN}(1: 1, \mathrm{v} / \mathrm{v})$ and lyophilized. Purification of the peptide was achieved by semi-preparative HPLC (Waters Delta 600 instrument) using linear gradients from 0 to $10 \% \mathrm{MeCN}$ over 2 min and 10 to $30 \% \mathrm{MeCN}$ over $10 \mathrm{~min}$. The purified peptide was characterized by analytical HPLC (10 to $40 \% \mathrm{MeCN}$ over $8 \mathrm{~min}, \mathrm{t}_{\mathrm{R}}=4.227$ min) and MALDI-TOF (Applied Biosystems, USA) (m/z calcd. for $\mathrm{C}_{38} \mathrm{H}_{67} \mathrm{~N}_{11} \mathrm{O}_{13} \mathrm{~S}: 917.46$, found: $\left.\left.918.30[\mathrm{M}+\mathrm{H}]^{+} ; 940.28[\mathrm{M}+\mathrm{Na}]^{+}\right) ; 956.25[\mathrm{M}+\mathrm{K}]^{+}\right)$.

\subsection{Synthesis of cyclic RGD peptide (cRGD)}

The cyclic peptide MPA-Ahx-Ahx-Ahx-cyclo(-RGDfK-) (cRGD) was synthesized as previously described ${ }^{19,43,44}$. In brief, the thiol-protected anchor MPA(Trt)-Ahx-Ahx-Ahx-OH (1 equiv), 1-hydroxy-7-azabenzotriazole (HOAt) (1.2 equiv) and $\mathrm{N}-[($ dimethylamino)-1H1,2,3-triazolo[4,5-b]pyridino-1-ylmethylene]-N-methylmethanaminium hexafluorophosphate (HATU) (1.2 equiv) were dissolved in anhydrous DMF $(0.022 \mathrm{mM})$ and pre-activated for $3 \mathrm{~h}$ at room temperature in the presence of DIEA (5 equiv). Next, cyclo(-R(Pbf)GD(OtBu)fK-) (1 equiv) dissolved in anhydrous DMF was added to the reaction mixture and allowed to react under stirring overnight at room temperature. After reaction, DMF was evaporated to 
dryness, a saturated solution of $\mathrm{NaHCO}_{3}$ was added and the crude product was extracted with EtOAc thrice. The organic layer was washed with brine, dried with $\mathrm{Na}_{2} \mathrm{SO}_{4}$ and evaporated. The peptide was next treated with TFA/ $\mathrm{H}_{2} \mathrm{O} / \mathrm{TIS}(95: 2.5: 2.5)$ for $1.5 \mathrm{~h}$. The peptide was finally precipitated with cold anhydrous diethyl ether, washed twice with this solvent and lyophilized. Semi-preparative HPLC purification (linear gradients from 0 to $10 \% \mathrm{MeCN}$ over $2 \mathrm{~min}$ and 10 to $40 \% \mathrm{MeCN}$ over $15 \mathrm{~min}$ ) yielded the peptide as a white powder. The purified peptide was characterized by analytical HPLC (10 to $40 \% \mathrm{MeCN}$ over $8 \mathrm{~min}, \mathrm{t}_{\mathrm{R}}=$ $6.578 \mathrm{~min}$ ) and MALDI-TOF (m/z calcd. for $\mathrm{C}_{48} \mathrm{H}_{78} \mathrm{~N}_{12} \mathrm{O}_{11} \mathrm{~S}$ : 1030.56 , found: 1031.39 $\left.\left.[\mathrm{M}+\mathrm{H}]^{+} ; 1053.37[\mathrm{M}+\mathrm{Na}]^{+}\right) ; 1069.35[\mathrm{M}+\mathrm{K}]^{+}\right)$.

\subsection{Sample biofunctionalization}

\subsubsection{Silanization}

Samples were silanized in order to covalently attach the molecules to the substrate. TiNbHf samples and Quartz Crystal Microbalance with Dissipation Monitoring (QCM-D) Ti sensors (QSX310, Q-Sense, Sweden) were first cleaned in an ultrasound bath with cyclohexane, isopropanol, ethanol, deionized water and acetone, and then cleaned and activated with oxygen plasma for $5 \mathrm{~min}$ at a $12 \mathrm{MHz}$ frequency in an Expanded Plasma Cleaner PDC-002 (Harrick Scientific Corporation, USA). Then, samples were immersed in a $0.08 \mathrm{M}$ solution of (3-aminopropyl)triethoxysilane (APTES, Sigma-Aldrich) in toluene (Sigma-Aldrich) at $70^{\circ} \mathrm{C}$ for $1 \mathrm{~h}$ under agitation in an inert atmosphere. After silanization, samples were ultrasonicated in toluene for $5 \mathrm{~min}$ and cleaned with toluene (3x), acetone (1x), isopropanol (3x), distilled water $(3 \mathrm{x})$, ethanol $(3 \mathrm{x})$ and acetone $(3 \mathrm{x})$. Subsequently aminosilanized samples were immersed in a $7.5 \mathrm{mM}$ solution of $\mathrm{N}$-succinimidyl-3-maleimidepropionate (SMP) in DMF for $1 \mathrm{~h}$ under agitation at room temperature. The cross-linked samples were rinsed in DMF $(3 \mathrm{x})$, acetone $(1 \mathrm{x})$, distilled water $(10 \mathrm{x})$, ethanol $(3 \mathrm{x})$ and acetone $(3 \mathrm{x})$ and dried with nitrogen. 


\subsubsection{Molecules immobilization}

linRGD and cRGD were used at a concentration of $100 \mu \mathrm{M}$ and CAS and HBII were used at a concentration of $100 \mu \mathrm{g} / \mathrm{ml}$ (concentrations optimized in previous studies in our group). FN (Sigma-Aldrich) was used at a $50 \mu \mathrm{g} / \mathrm{ml}$ concentration. Solvent for all molecules was phosphate buffered saline (PBS, Invitrogen).

Ti25Nb21Hf silanized samples were incubated overnight with a $100 \mu \mathrm{l}$ drop of linRGD, cRGD, FN, CAS, HBII, respectively, or combinations of different proportions of CAS and HBII (30:70, 50:50 or 70:30 respectively, v/v). After incubation, samples were rinsed in PBS (x3) and blocked with 1\% bovine serum albumin (BSA, Sigma-Aldrich) in PBS for 30 min. Samples were sterilized by immersion in ethanol for 30 min followed by 3 rinses in PBS.

\subsection{Quartz crystal microbalance with monitoring dissipation (QCM-D)}

The QCM-D was used to study the biomolecules adsorption onto silanized Ti sensors. The QCM-D (D300, Q-Sense, Sweden) measurements were performed at $37^{\circ} \mathrm{C}$ by monitoring changes in frequency, $\Delta \mathrm{f}(\mathrm{Hz})$, and dissipation, $\Delta \mathrm{D}\left(\times 10^{-6}\right)$, in real-time using Qsoft software (Q-Sense). All raw data was analyzed using QTools software (Q-Sense). Frequency and dissipation curves were fitted to a Voigt viscoelastic model to yield relevant mass, thickness, and kinetic information. The description of the Voigt model and details on its implementation using a QCM-D are reported elsewhere. ${ }^{45,46}$

Monitoring of the adsorption was conducted first by completely stabilizing the baseline with PBS for 30-60 min. Then, the biomolecule of study was introduced at a concentration specified in section 2.5.2, and maintained in the sensor chamber for $60 \mathrm{~min}$. Finally, the biomolecules weakly bound to the surface were rinsed with PBS for $10 \mathrm{~min}$. 


\subsection{X-ray photoelectron spectroscopy (XPS)}

XPS measurements were used to analyze the chemical composition of the samples after biomolecule immobilization. To this end, samples were silanized and coated as explained in section 2.5, and analyzed using an XPS system (SPECS Surface Nano Analysis GmbH, Berlin, Germany) equipped with a Mg anode XR50 source operating at $150 \mathrm{~W}$ and a Phoibos 150 MCD-9 detector. Detector pass energy was fixed at $25 \mathrm{eV}$ with $0.1 \mathrm{eV}$ steps to record high resolution spectra at a pressure below $7.5 \times 10-9$ mbar. Data was analyzed using CasaXPS software (Version 2.3.16, Casa Software Ltd., Teignmouth, UK). Binding energies were calibrated with the $\mathrm{C} 1 \mathrm{~s}$ signal located at $284.8 \mathrm{eV}$.

\subsection{Cell culture}

rMSCs were extracted from femurs of young Lewis rats and expanded in Advanced DMEM supplemented with $10 \%$ fetal bovine serum (FBS), $20 \mathrm{mM}$ HEPES buffer solution, penicillin/streptomycin antibiotics (50 U/ml and $50 \mu \mathrm{g} / \mathrm{ml}$, respectively), $2 \mathrm{mM}$ L-glutamine (all from Invitrogen) at $37^{\circ} \mathrm{C}$ with $5 \% \mathrm{CO}_{2}$ and $95 \%$ relative humidity. Cells from passage 5 were used in all the experiments.

\subsection{Cell adhesion}

Cells (10.000 cells/sample) were seeded in each sample with serum-free medium and allowed to adhere for $4 \mathrm{~h}$. Then, cells were rinsed with PBS (x3) and lysed with $300 \mu$ of Mammalian Protein Extraction Reagent (M-PER, Thermo Fisher, USA). The number of cells adhered was determined using the Cytotoxicity Detection Kit ${ }^{\text {PLUS }}$ (LDH) (Roche, USA) following the manufacturer's instructions. The lactate dehydrogenase (LDH) activity was measured spectrophotometrically at $492 \mathrm{~nm}$ in a PowerWave HT microplate reader (Bio-Tek, USA). A calibration curve with decreasing number of cells was performed to express the results as cell number. 


\subsection{Cell spreading}

Cells (25.000 cells/sample) were seeded in each sample with serum-free medium and fixed 4 h after seeding with 4\% paraformaldehyde (Sigma-Aldrich) for $30 \mathrm{~min}$. Fixed cells were permeabilized with $0.05 \%$ Triton X-100 in PBS at room temperature for 20 min and washed with $20 \mathrm{mM}$ glycine in PBS (x3). Then samples were blocked with $1 \%$ BSA in PBS and incubated for $30 \mathrm{~min}$. Next, cells were incubated with mouse anti-vinculin (1:100; Invitrogen) for $1 \mathrm{~h}$ and rinsed with $20 \mathrm{mM}$ glycine in PBS. Afterwards, samples were incubated with Alexa Fluor ${ }^{\circledR} 488$ goat anti-mouse antibody (1:1000; Invitrogen) and TRITC-phalloidin (1:300; Invitrogen) in the dark for $1 \mathrm{~h}$. After incubation, samples were washed with $20 \mathrm{mM}$ glycine in PBS (x3) and nuclei were counterstained with DAPI (1:1000; Invitrogen). Finally, samples were mounted in Mowiol ${ }^{\circledR}$ 4-88 (Sigma-Aldrich) before visualizing in an E600 fluorescence microscope (Nikon Corp., Japan). Five images at 10X magnification from different areas of each sample were acquired and cell spreading was determined measuring the area of the cells using ImageJ software (National Institute of Health, USA).

\subsection{Cell proliferation}

Cells were seeded in serum-free medium at a density of 10.000 cells/sample. After $4 \mathrm{~h}$, medium was aspirated, and cells were cultured for 7 days, 14 days and 21 days in complete medium. After each incubation period, cells were rinsed in PBS (x3) and lysed with $300 \mu 1$ of M-PER. The number of cells adhered was determined using the Cytotoxicity Detection Kit PLUS $(L D H)$ as described above.

\subsection{Cell differentiation}

Lysed cells from the proliferation assay were also used for alkaline phosphatase (ALP) detection using the SensoLyte ${ }^{\circledR}$ pNPP Alkaline Phosphatase Assay Kit (AnaSpec Inc., USA) following the manufacturer's guidelines. Reactions were incubated at $37^{\circ} \mathrm{C}$ for $30 \mathrm{~min}$. After 
incubation, values of absorbance were read in a PowerWave HT microplate reader at $405 \mathrm{~nm}$. A calibration curve was prepared using purified ALP from the kit. Results were normalized versus cell number and time of incubation.

\subsection{Statistical analysis}

Experiments were performed in duplicate using three replicates per each group. All data are presented as mean values \pm standard deviations. A non-parametric Kruskal-Wallis test followed by Mann-Whitney test with Bonferroni correction was used to determine statistical significant ( $p$-value $<0.05$ ) differences between the means of the different groups.

\section{RESULTS}

\subsection{Physicochemical characterization}

\subsubsection{QCM-D}

The thickness and surface mass density of the adlayer of immobilized biomolecule on silanized $\mathrm{Ti}$ sensors determined by QCM-D analysis is shown in Table 1. Figure S1 (supplementary material) shows the changes in frequency and dissipation over time recorded during the adsorption of the biomolecules. In all cases, the frequency rapidly decreased after injection, reaching values of saturation after 10 and $15 \mathrm{~min}$ for the peptides and protein fragments, respectively. Moreover, dissipation coefficients showed small changes during the adsorption of peptides, while very high values were reached for HBII and to a slightly lower extent for the CAS protein fragment. The final adsorbed mass was considerably higher for the protein fragments $\left(609.1 \mathrm{ng} / \mathrm{cm}^{2}\right.$ for CAS, $823.8 \mathrm{ng} / \mathrm{cm}^{2}$ for HBII) than for the peptides (220.1 $\mathrm{ng} / \mathrm{cm}^{2}$ for linRGD and $200.0 \mathrm{ng} / \mathrm{cm}^{2}$ for cRGD). 


\subsubsection{XPS}

The analysis of the chemical composition of the surfaces by XPS is summarized in Table 2 . In general, the presence of the biomolecules increased the percentage of $\mathrm{C} 1 \mathrm{~s}$ and $\mathrm{N} 1 \mathrm{~s}$ and decreased the observed amounts of O $1 \mathrm{~s}$, Si $2 \mathrm{p}$ and Ti $2 \mathrm{p}$ compared to control (Ctrol) nonfunctionalized surfaces. These effects were more pronounced for the protein fragments (CAS and HBII) than for the peptides (linRGD and cRGD).

\subsection{Cell adhesion}

\subsubsection{Number of cells adhered}

The number of cells adhered onto each biofunctionalized surface (Fig. 1) differed depending on the immobilized molecule. Surfaces coated with linRGD, cRGD, CAS or HBII, respectively, showed a significant improvement on cell adhesion compared to $F N(p<0.05)$. There were no statistical differences on cell numbers between the peptides and the protein fragments. On the other hand, the different combinations of CAS and HB II fragments triggered different cell adhesion responses. Low concentrations of CAS (30\% and 50\%) stimulated an adhesion similar to that of $\mathrm{FN}$, whilst a higher concentration (70\%) originated a response comparable to that of linRGD, cRGD, CAS or HBII fragments alone.

\subsubsection{Cell spreading}

The area of cells adhered on the different biofunctionalized surfaces is shown in Fig. 2. The spreading obtained for cells in contact with linRGD and HBII respectively, was statistically lower $(p<0.05)$ than that obtained for cells in contact with FN, cRGD and CAS. When both CAS and HB II recombinant fragments were mixed, the proportion of each of the two fragments influenced cell spreading. Low percentages $(30 \%$ and $50 \%)$ of CAS induced values of cell spreading close to that found on FN-coated surfaces, whereas higher values of 
CAS (70\%) led to lower projected cell areas, with values similar to those of the linear RGD peptide and the HBII fragment alone.

\subsubsection{Cell morphology}

The formation of actin stress fibers (in red) was stimulated by linRGD (Fig. 3B), cRGD (Fig. 3C) and CAS (Fig. 3D), although structures resembling focal contacts were not seen in the cells in contact with these biomolecules. Cells in contact with HBII (Fig. 3E) were not able to generate neither actin filaments nor focal adhesions and showed ruffled borders. Noteworthy, when both CAS and HBII were mixed with low percentages of CAS (Figs. 3F and 3G) cells showed a cytoskeleton conformation closer to that of FN compared to the other biomolecules, whereas the presence of CAS in high percentage (Fig. 3H) showed a cytoskeleton similar to the CAS fragment alone.

\subsection{Cell proliferation}

The proliferation of rMSCs on the different biofunctionalized substrates after 4 h, 7 days, 14 days and 21 days in culture is shown in Fig. 4. Although cells cultured with linRGD, cRGD, CAS or HBII, respectively, supported cell proliferation within the initial 7 days of incubation, the number of cells on these surfaces did not reach the values obtained with FN coating, which showed the highest values of cell growth at 21 days. Noteworthy, when CAS and HBII recombinant fragments were mixed using less than $70 \%$ of CAS, the proliferation levels were closer to FN samples. In contrast, for higher percentages of CAS fragment proliferation rates were similar to short peptides or recombinant fragments separately.

\subsection{Cell differentiation}

Fig. 5 shows the ALP activity levels of rMSCs after 7, 14 and 21 days in culture. The first 7 days in culture, ALP levels for cells cultured on HBII and high percentage of CAS (70\%) were significantly higher compared with FN and the other molecules, which showed levels of 
ALP equivalent to that of FN. After two weeks in culture, ALP from cRGD, CAS and CAS $(50 \%)$ was reduced whilst the other surfaces showed similar levels compared with FN and between them. However, cells cultured on cRGD or CAS fragment exhibited an increase on ALP levels 21 days after seeding, reaching levels similar to those of FN. Noteworthy, HBIIcoated surfaces stimulated significantly higher ALP levels than linRGD, cRGD, CAS and FN at all time points, reaching the highest levels of ALP production after 21 days of incubation. Combination of the HBII with a high percentage of CAS (70\%) maintained this high ALP expression. In contrast, ALP levels were significantly reduced when HBII was mixed with lower concentrations of CAS (30\% and $50 \%)$.

\section{DISCUSSION}

One approach to improve osseointegration in metallic implants is the immobilization of bioactive molecules on their surface. Such modifications are usually achieved by physisorption or covalent bonding. Physisorption is a non-covalent method based on Van der Waals interactions and hydrogen bonds, which are weak and unstable interactions. In contrast, the use of silane chemistry is a preferred and well-extended method for covalently bounding bioactive molecules onto metallic surfaces as it provides a strong and stable binding on the surfaces. ${ }^{22,47}$ In this regard, APTES has been extensively used for surface functionalization purposes and demonstrated its suitability for the immobilization of bioactive molecules onto $\mathrm{Ti}^{22}$ and TiNbHf alloy. ${ }^{48}$ Moreover, in a recent study we demonstrated that the use of APTES provides a more homogenous layer of biomolecule attachment in both Ti and TiNbHf alloy compared to physisorption. ${ }^{49}$ Hence, in the present work APTES was chosen as linker molecule to immobilize the different bioactive molecules onto a recently developed low modulus TiNbHf alloy.

As previously introduced, the binding of synthetic RGD peptides to Ti surfaces and TiNbHf alloys using this silane has been recently characterized, and yielded a dense and homogenous 
layer of peptide on the surfaces. ${ }^{49}$ The number and density of molecules immobilized on these surfaces with this method has been reported in a large number of previous studies. ${ }^{50,51}$ However, no literature was available on the relative adsorption kinetics of the CAS and HBII fragments on TiNbHf via APTES. QCM-D results indicated a successful attachment of both proteins and peptides on the Ti sensors, reaching values of saturation after $10 \mathrm{~min}$ and $15 \mathrm{~min}$ of incubation, respectively. Rinsing in PBS resulted in minor protein detachment, proving the stability of the coatings. The amount of adsorbed protein was slightly different for each fragment (i.e. HBII adsorbed mass was 1.3 fold higher than that of CAS). This observation might be attributed to the distinct conformation and chemical sequence of the proteins, which in turn results in different values of protein binding. As expected, surface mass density was lower for peptides compared to protein fragments. The amount of adhered linRGD was slightly higher than cRGD but differences were not statistically significant. Dissipation shift plots indicated that during HBII protein adsorption, water was incorporated and trapped in the layer of protein, as seen in the increasing $\triangle \mathrm{D}$. CAS protein layer was less viscoelastic and both peptide adsorbed layers were more rigid compared to the HBII protein fragments layer. XPS data confirmed QCM-D results and showed a successful biofunctionalization of the surfaces. The observed increases in $\mathrm{C} 1 \mathrm{~s}$, and especially in $\mathrm{N} 1 \mathrm{~s}$, are common indicators of biomolecule attachment (i.e. amide bonds). ${ }^{22,27,50,51}$ The reduction in the detectable signals of Ti $2 p, \mathrm{O} 1 \mathrm{~s}$, and $\mathrm{Si} 2 \mathrm{p}$ is also consistent with the presence of biomolecules, which mask the detection of Ti oxide and the silane layer. The binding of the protein fragments yielded the highest variations in chemical composition (e.g. the percentage of $\mathrm{N} 1 \mathrm{~s}$ ) in comparison to the RGD peptides. This observation is well in agreement with QCM-D values, which indicated that the amount of proteins bound to the surfaces was higher than that of the peptides.

The interaction of cells with the different functionalized surfaces exhibited substantially different behaviours. Both recombinant FN fragments, CAS and HBII, stimulated better cell 
adhesion than the whole FN, and similarly to RGDs. The higher activity of a recombinant FNIII $_{7-10}$ fragment compared to plasma human $\mathrm{FN}$ has been previously described by the group of García ${ }^{30}$ and associated with an enhanced affinity for integrin $\alpha 5 \beta 1$. The higher number of attached cells observed for RGD peptides could also be attributed to a higher availability of cell adhesive motifs per area compared to native FN. Although previous studies demonstrated better cell adhesion on CAS fragment than on RGDs, ${ }^{28-30}$ these differences tend to disappear in saturated surface densities. ${ }^{28}$ Noteworthy, HBII also stimulated high cell adhesion numbers. This may be explained by the fact that cell surface HSPGs may act as receptors for the HB fragment ${ }^{52,53}$ and that integrin receptors $\alpha 4 \beta 1$ and $\alpha v \beta 5$ may interact with specific sequences in this region of $F N{ }^{52,54}$

Although the number of cells was high in both FN fragments and RGDs, these cell adhesive motifs were not enough to stimulate cell spreading to similar levels than the native FN. In addition, the number of focal adhesions on these surfaces was lower compared to $\mathrm{FN}$, suggesting that their formation depends on the interaction of cell adhesion sequences with other binding sites present in FN. ${ }^{55}$ This scenario completely changed when both recombinant FN fragments were mixed on the same surface. Although the number of cells increased while CAS concentration was incremented, cellular spreading, cytoskeletal organization and focal adhesion formation were improved with higher concentrations of HBII $(\geq 50 \%)$. The observed critical biological role of the HBII domain is due to the presence of actin-organizing elements located in the type $\mathrm{III}_{13}$ repeat that stimulate the formation of focal adhesions. ${ }^{55}$ In this study we have shown that the HBII fragment alone does not support cell spreading and cytoskeletal formation on the surfaces, however, in combination with small percentages of the CAS domain effectively stimulates the formation of stress fibers and focal contacts, reaching cell morphologies similar to $\mathrm{FN} .{ }^{54,56,57}$ 
Integrin mediated adhesion plays a major role in the regulation of cell proliferation, since it stimulates crucial regulatory pathways of cell growth. ${ }^{58}$ However, proliferation not only depends on cell adhesive mechanisms but also on the interaction with soluble growth factors. The growth factor receptor signalling is moreover highly regulated by integrin expression and activity. ${ }^{59,60}$ In the present study, RGDs and the recombinant FN fragments did not induce cell proliferation at levels comparable to that of full-length FN, probably due to the lack of cooperation between adhesion and growth factor signalling. In contrast, the combination of the CAS with high concentrations of the HBII domain $(\geq 50 \%$ ) effectively improved proliferation of rMSCs. This could be attributed to the fact that besides the cell adhesion cooperative activity, HBII may also act as a growth factor binding domain. This enhancement in cell proliferation was also observed in previous studies by Kim et al. ${ }^{53}$ and Martino et al., ${ }^{33}$ although in their studies a molecule containing both CAS and HBII fragments fused was used instead.

Finally, the stimulation of MSCs to differentiate into the osteoblastic lineage, also known as osseoinduction, is a critical step to ensure the biomaterial osseointegration. The secretion of ALP has been widely used as a marker for osteoblastic differentiation. In the present study, surface functionalization with a synthetic linRGD peptide was enough for stimulating rMSCs differentiation despite the low integrin-specificity described for linear peptides. ${ }^{36,61}$

In the present study, surface functionalization with a synthetic linRGD peptide was enough for stimulating rMSCs differentiation. However, presentation of the RGD motif in a cyclic conformation reduced the expression of ALP levels. This result should not come as a surprise because cRGD shows a higher specificity than linRGD for integrins $\alpha v \beta 3$ and $\alpha v \beta 5$, but not towards $\alpha 5 \beta 1$, which is well known to induce osteogenic differentiation. ${ }^{62,63}$ Noteworthy, the presence of HBII yielded the highest levels of ALP activity probably due to the aforementioned capacity to bind diverse growth factors, which may include BMP-2 and 
BMP-7 present in the serum. ${ }^{41}$ However, the combination of HBII and CAS fragments yielded unexpected results: whereas low percentages of HBII retained high values of ALP expression (CAS-HBII 70:30) higher amounts reduced this activity (CAS-HBII 50:50 and CAS-HBII 30:70) (Fig. 5).

The equimolar presentation of CAS and HBII (50:50) should support similar biological profiles than full length FN. As a matter of fact, comparable cell responses were observed in terms of cell spreading, cytoskeleton formation and proliferation (Fig. 6). In this case, the reduced osteogenic capacity could probably respond to two factors: an insufficient quantity of HBII motifs available for growth factor interaction or the absence of other regulatory sequences present in FN, which may account for the osteogenic activity of the native protein.

It was even more intriguing that an increase in the proportion of HBII (CAS-HBII 30:70) did not stimulate osteoblastic differentiation. We hypothesized that the reduced amount of CAS fragment available for integrin binding would not be enough for generating stable cellular adhesions and focal contacts, thereby engaging part of the HBII fragments in cell adhesion/cytoskeleton organization. This would explain why even if the proportion of CAS is reduced in the mixture CAS-HBII (30:70), the other parameters of cell behavior remain comparable to those of FN (Fig. 6). This "co-adhesive" role for HBII would, in turn, diminish its capacity to sequester growth factors and thus its osteogenic activity. Only when a larger amount of HBII is present (HBII alone) both an adhesive and an osteogenic effect can be maintained.

This hypothesis could also explain the opposite situation (CAS-HBII 70:30). In this context, the high amount of CAS would be sufficient to efficiently stimulate cell adhesion and cytoskeleton organization. This would keep a higher number of HBII fragments free for interaction with growth factors increasing the ALP levels. 


\section{CONCLUSIONS}

In the present study cell response to functionalised $\mathrm{Ti} 25 \mathrm{Nb} 21 \mathrm{Hf}$ alloy with two different recombinant FN fragments was studied. The results demonstrate that the mixture of CAS and HBII fragments improves cellular behaviour compared to fragments alone or synthetic RGD peptides, being a promising strategy for biomaterial implantation purposes. This response may be modulated depending on the percentage of each fragment.

When dealing with combinations of molecules that are bifunctional and/or share a similar biological function, it is important to highlight that reducing the percentage of one of the bioactive molecules in the mixture can modify the biological profile of the other one. In the present study, we observed that the reduction on the amount of cell adhesive motifs (CAS) in the mixture was accompanied with a decrease in the osteogenic activity of the HBII fragment. We hypothesized that this effect was attributed to the fact that the low percentage of CAS engaged HBII in cell adhesive processes, thus reducing its capacity to interact with growth factors and hence its osteogenic capacity.

Therefore, it should be taken into account that the equimolar presentation of two bioactive molecules may not always be an optimal approach when these molecules have partially overlapping biological roles. In these instances, the study of different percentages of each motif is recommended.

\section{ACKNOWLEDGEMENTS}

The authors would like to thank the Ministry of Economy and Competitiveness (MINECO) of the Spanish Government for financial support through MAT2012-30706 project co-funded by the EU through European Regional Development Funds and the FI fellowship of the AGAUR Agency. C. M.-M. thanks the support of the Secretary for Universities and Research of the Ministry of Economy and Knowledge of the Government of Catalonia (2011-BP-B00042) and the People Programme (Marie Curie Actions) of the European Union's Seventh 
Framework Programme (FP7-PEOPLE-2012-CIG, REA Grant Agreement 321985).

Technical assistance of Mrs. Montse Dominguez with XPS measurements is greatly appreciated. 


\section{REFERENCES}

(1) Titanium in Medicine: material Science, Surface Science, Engineering, Biological Responses, and Medical Applications; Brunette, D. M., Tengvall, P., Textor, M., Thomsen, P., Eds.; Springer,Berlin, 2001.

(2) Ridzwan, M. I. Z.; Shuib, S.; Hassan, A. Y.; Shokri, A. A.; Mohamad Ibrahim, M. N. Problem of Stress Shielding and Improvement to the Hip Implant Designs: A Review. J. Med. Sci. 2007, 7 (3), 460-467.

(3) Nobuhito, S.; Niinomi, M.; Toshikazu, A.; Takashi, S.; Tadahiko, F. Effects of Alloying Elements on Elastic Modulus of Ti-Nb-Ta-Zr System Alloy for Biomedical Applications. Mater. Sci. Forum 2004, 449-452, 1269-1272.

(4) Hon, Y. H.; Wang, J. Y.; Pan, Y. N. Influence of Hafnium Content on Mechanical Behaviors of Ti-40Nb-xHf Alloys. Mater. Lett. 2004, 58 (25), 3182-3186.

(5) Li, Y.; Yang, C.; Zhao, H.; Qu, S.; Li, X.; Li, Y. New Developments of Ti-Based Alloys for Biomedical Applications. Materials (Basel) 2014, 7 (3), 1709-1800.

(6) Matsuno, H.; Yokoyama, A.; Watari, F.; Uo, M.; Kawasaki, T. Biocompatibility and Osteogenesis of Refractory Metal Implants, Titanium, Hafnium, Niobium, Tantalum and Rhenium. Biomaterials 2001, 22 (11), 1253-1262.

(7) Amick, D. D. Characterization of TiNbHf Alloys for Potential Medical Dental Applications. M.S. Thesis, University of Oregon, 1993.

(8) Gonzalez, M.; Peña, J.; Manero, J. M.; Arciniegas, M.; Gil, F. J. Design and Characterization of New Ti-Nb-Hf Alloys. J. Mater. Eng. Perform. 2009, 18 (5), 490495. 
(9) Herranz-Diez, C.; Gil, F.; Guillem-Marti, J.; Manero, J. Mechanical and Physicochemical Characterization along with Biological Interactions of a New Ti25Nb21Hf Alloy for Bone Tissue Engineering. J. Biomater. Appl. 2015, 30 (2), 171181.

(10) Mas-Moruno, C.; Espanol, M.; Montufar, E. B.; Mestres, G.; Aparicio, C.; Gil, F. J.; Ginebra, M. Bioactive Ceramic and Metallic Surfaces for Bone Engineering. In Biomaterials Surface Science; Taubert, A., Mano, J. F., Rodríguez-Cabello, J. C., Eds.; Wiley-VCH Verlag GmbH \& Co. KGaA: Weinheim, Germany, 2013; pp 337-374.

(11) Shekaran, A.; García, A. J. Extracellular Matrix-Mimetic Adhesive Biomaterials for Bone Repair. J. Biomed. Mater. Res., Part A 2011, 96 A (1), 261-272.

(12) Tejero, R.; Anitua, E.; Orive, G. Toward the Biomimetic Implant Surface: Biopolymers on Titanium-Based Implants for Bone Regeneration. Prog. Polym. Sci. 2014, 39 (7), 1406-1447.

(13) Sverzut, A. T.; Crippa, G. E.; Morra, M.; de Oliveira, P. T.; Beloti, M. M.; Rosa, A. L. Effects of Type I Collagen Coating on Titanium Osseointegration: Histomorphometric, Cellular and Molecular Analyses. Biomed. Mater.(Bristol, U.K.) 2012, 7 (3), 035007.

(14) Rivera-Chacon, D. M.; Alvarado-Velez, M.; Acevedo-Morantes, C. Y.; Singh, S. P.; Gultepe, E.; Nagesha, D.; Sridhar, S.; Ramirez-Vick, J. E. Fibronectin and Vitronectin Promote Human Fetal Osteoblast Cell Attachment and Proliferation on Nanoporous Titanium Surfaces. J. Biomed. Nanotechnol. 2013, 9 (6), 1092-1097.

(15) Hersel, U.; Dahmen, C.; Kessler, H. RGD Modified Polymers: Biomaterials for Stimulated Cell Adhesion and Beyond. Biomaterials 2003, 24 (24), 4385-4415.

(16) Williams, D. F. The Role of Short Synthetic Adhesion Peptides in Regenerative 
Medicine; the Debate. Biomaterials 2011, 32 (18), 4195-4197.

(17) Auernheimer, J.; Zukowski, D.; Dahmen, C.; Kantlehner, M.; Enderle, A.; Goodman, S. L.; Kessler, H. Titanium Implant Materials with Improved Biocompatibility through Coating with Phosphonate-Anchored Cyclic RGD Peptides. Chembiochem 2005, 6 (11), 2034-2040.

(18) Kilian, K. A.; Mrksich, M. Directing Stem Cell Fate by Controlling the Affinity and Density of Ligand-Receptor Interactions at the Biomaterials Interface. Angew. Chem., Int. Ed. Engl. 2012, 51 (20), 4891-4895.

(19) Mas-Moruno, C.; Dorfner, P. M.; Manzenrieder, F.; Neubauer, S.; Reuning, U.; Burgkart, R.; Kessler, H. Behavior of Primary Human Osteoblasts on Trimmed and Sandblasted Ti6Al4V Surfaces Functionalized with Integrin $\alpha v \beta 3$-Selective Cyclic RGD Peptides. J. Biomed. Mater. Res., Part A 2013, 101 (1), 87-97.

(20) Rechenmacher, F.; Neubauer, S.; Polleux, J.; Mas-Moruno, C.; De Simone, M.; Cavalcanti-Adam, E. A.; Spatz, J. P.; Fässler, R.; Kessler, H. Functionalizing avß3- or $\alpha 5 \beta 1$-Selective Integrin Antagonists for Surface Coating: A Method to Discriminate Integrin Subtypes in Vitro. Angew. Chem., Int. Ed. Engl. 2013, 52 (5), 1572-1575.

(21) Rechenmacher, F.; Neubauer, S.; Mas-Moruno, C.; Dorfner, P. M.; Polleux, J.; Guasch, J.; Conings, B.; Boyen, H.-G.; Bochen, A.; Sobahi, T. R.; Burgkart, R.; Spatz, J. P.; Fässler, R.; Kessler, H. A Molecular Toolkit for the Functionalization of Titanium-Based Biomaterials That Selectively Control Integrin-Mediated Cell Adhesion. Chemistry 2013, 19 (28), 9218-9223.

(22) Fraioli, R.; Rechenmacher, F.; Neubauer, S.; Manero, J. M.; Gil, J.; Kessler, H.; MasMoruno, C. Mimicking Bone Extracellular Matrix: Integrin-Binding Peptidomimetics 
Enhance Osteoblast-like Cells Adhesion, Proliferation, and Differentiation on Titanium. Colloids Surf., B 2015, 128, 191-200.

(23) Dahmen, C.; Auernheimer, J.; Meyer, A.; Enderle, A.; Goodman, S. L.; Kessler, H. Improving Implant Materials by Coating with Nonpeptidic, Highly Specific Integrin Ligands. Angew. Chem., Int. Ed. Engl. 2004, 43 (48), 6649-6652.

(24) Bell, B. F.; Schuler, M.; Tosatti, S.; Textor, M.; Schwartz, Z.; Boyan, B. D. Osteoblast Response to Titanium Surfaces Functionalized with Extracellular Matrix Peptide Biomimetics. Clin. Oral Implants Res. 2011, 22 (8), 865-872.

(25) Yin, W.-N.; Cao, F.-Y.; Han, K.; Zeng, X.; Zhuo, R.-X.; Zhang, X.-Z. The Synergistic Effect of a BMP-7 Derived Peptide and Cyclic RGD in Regulating Differentiation Behaviours of Mesenchymal Stem Cells. J. Mater. Chem. B 2014, 2 (47), 8434-8440.

(26) Lin, W.; Junjian, C.; Chengzhi, C.; Lin, S.; Sa, L.; Li, R.; Yingjun, W. MultiBiofunctionalization of a Titanium Surface with a Mixture of Peptides to Achieve Excellent Antimicrobial Activity and Biocompatibility. J. Mater. Chem. B 2015, 3 (1), $30-33$.

(27) Mas-Moruno, C.; Fraioli, R.; Albericio, F.; Manero, J. M.; Gil, F. J. Novel PeptideBased Platform for the Dual Presentation of Biologically Active Peptide Motifs on Biomaterials. ACS Appl. Mater. Interfaces 2014, 6 (9), 6525-6536.

(28) Petrie, T. A.; Capadona, J. R.; Reyes, C. D.; García, A. J. Integrin Specificity and Enhanced Cellular Activities Associated with Surfaces Presenting a Recombinant Fibronectin Fragment Compared to RGD Supports. Biomaterials 2006, 27 (31), 54595470.

(29) Petrie, T. A.; Raynor, J. E.; Reyes, C. D.; Burns, K. L.; Collard, D. M.; García, A. J. 
The Effect of Integrin-Specific Bioactive Coatings on Tissue Healing and Implant Osseointegration. Biomaterials 2008, 29 (19), 2849-2857.

(30) Petrie, T. A.; Reyes, C. D.; Burns, K. L.; García, A. J. Simple Application of Fibronectin-Mimetic Coating Enhances Osseointegration of Titanium Implants. $J$. Cell. Mol. Med. 2009, 13 (8b), 2602-2612.

(31) Martino, M. M.; Mochizuki, M.; Rothenfluh, D. A.; Rempel, S. A.; Hubbell, J. A.; Barker, T. H. Controlling Integrin Specificity and Stem Cell Differentiation in 2D and 3D Environments through Regulation of Fibronectin Domain Stability. Biomaterials 2009, 30 (6), 1089-1097.

(32) Traub, S.; Morgner, J.; Martino, M. M.; Höning, S.; Swartz, M. A.; Wickström, S. A.; Hubbell, J. A.; Eming, S. A. The Promotion of Endothelial Cell Attachment and Spreading Using FNIII10 Fused to VEGF-A165. Biomaterials 2013, 34 (24), 59585968.

(33) Martino, M. M.; Tortelli, F.; Mochizuki, M.; Traub, S.; Ben-David, D.; Kuhn, G. A.; Müller, R.; Livne, E.; Eming, S. A.; Hubbell, J. A. Engineering the Growth Factor Microenvironment with Fibronectin Domains to Promote Wound and Bone Tissue Healing. Sci. Transl. Med. 2011, 3 (100), 100ra89.

(34) Martino, M. M.; Briquez, P. S.; Güç, E.; Tortelli, F.; Kilarski, W. W.; Metzger, S.; Rice, J. J.; Kuhn, G. A.; Müller, R.; Swartz, M. A.; Hubbell, J. A. Growth Factors Engineered for Super-Affinity to the Extracellular Matrix Enhance Tissue Healing. Science 2014, 343 (6173), 885-888.

(35) Pankov, R.; Yamada, K. M. Fibronectin at a Glance. J. Cell Sci. 2002, 115 (20), 38613863. 
(36) Aota, S.; Nomizy, M.; Yamada, J. M. The Short Amino Acid Sequence Pro-His-SerArg-Asn in Human Fibronectin Enhances Cell-Adhesive Function. J. Biol. Chem. 1994, 269 (40), 24756-24761.

(37) Ku, Y.; Chung, C.-P.; Jang, J.-H. The Effect of the Surface Modification of Titanium Using a Recombinant Fragment of Fibronectin and Vitronectin on Cell Behavior. Biomaterials 2005, 26 (25), 5153-5157.

(38) Agarwal, R.; González-García, C.; Torstrick, B.; Guldberg, R. E.; Salmerón-Sánchez, M.; García, A. J. Simple Coating with Fibronectin Fragment Enhances Stainless Steel Screw Osseointegration in Healthy and Osteoporotic Rats. Biomaterials 2015, 63, $137-145$.

(39) Sarrazin, S.; Lamanna, W. C.; Esko, J. D. Heparan Sulfate Proteoglycans. Cold Spring Harbor Perspect. Biol. 2011, 3 (7), a004952.

(40) Elfenbein, A.; Simons, M. Syndecan-4 Signaling at a Glance. J. Cell Sci. 2013, 126 (Pt 17), 3799-3804.

(41) Martino, M. M.; Hubbell, J. A. The 12th-14th Type III Repeats of Fibronectin Function as a Highly Promiscuous Growth Factor-Binding Domain. FASEB J. 2010, $24(12), 4711-4721$.

(42) Albericio, F. Developments in Peptide and Amide Synthesis. Curr. Opin. Chem. Biol. 2004, 8 (3), 211-221.

(43) Kantlehner, M.; Schaffner, P.; Finsinger, D.; Meyer, J.; Jonczyk, A.; Diefenbach, B.; Nies, B.; Hölzemann, G.; Goodman, S. L.; Kessler, H. Surface Coating with Cyclic RGD Peptides Stimulates Osteoblast Adhesion and Proliferation as Well as Bone Formation. Chembiochem 2000, 1 (2), 107-114. 
(44) Haubner, R.; Gratias, R.; Diefenbach, B.; Goodman, S. L.; Jonczyk, A.; Kessler, H. Structural and Functional Aspects of RGD-Containing Cyclic Pentapeptides as Highly Potent and Selective Integrin $\alpha$ V $\beta 3$ Antagonists. J. Am. Chem. Soc. 1996, 118 (32), $7461-7472$.

(45) Höök, F.; Kasemo, B.; Nylander, T.; Fant, C.; Sott, H. Variations in Coupled Water, Viscoelastic Properties, and Film Thickness of a Mefp-1 Protein Film during Adsorption and Cross-Linking: A Quartz Crystal Microbalance with Dissipation Monitoring, Ellipsometry, and Surface Plasmon Resonance Study. Anal. Chem. 2001, $73,5796-5804$.

(46) Pegueroles, M.; Tonda-Turo, C.; Planell, J. A.; Gil, F. J.; Aparicio, C. Adsorption of Fibronectin, Fibrinogen, and Albumin on TiO2: Time-Resolved Kinetics, Structural Changes, and Competition Study. Biointerphases 2012, 7 (1), 1-13.

(47) Chen, X.; Sevilla, P.; Aparicio, C. Surface Biofunctionalization by Covalent CoImmobilization of Oligopeptides. Colloids Surf., B 2013, 107, 189-197.

(48) Paredes, V.; Salvagni, E.; Rodríguez-Castellon, E.; Gil, F. J.; Manero, J. M. Study on the Use of 3-Aminopropyltriethoxysilane and 3-Chloropropyltriethoxysilane to Surface Biochemical Modification of a Novel Low Elastic Modulus Ti-Nb-Hf Alloy. J. Biomed. Mater. Res., Part B 2014, 103 (3), 495-502.

(49) Herranz-Diez, C.; Li, Q.; Lamprecht, C.; Mas-Moruno, C.; Neubauer, S.; Kessler, H.; Manero, J. M.; Guillem-Martí, J.; Selhuber-Unkel, C. Bioactive Compounds Immobilized on Ti and TiNbHf: AFM-Based Investigations of Biofunctionalization Efficiency and Cell Adhesion. Colloids Surf., B 2015, 136, 704-711.

(50) Xiao, S.-J.; Textor, M.; Spencer, N. D.; Sigrist, H. Covalent Attachment of Cell- 
Adhesive, (Arg-Gly-Asp)-Containing Peptides to Titanium Surfaces. Am. Chem. Soc. 1998, 14 (19), 5507-5516.

(51) Xiao, S. J.; Textor, M.; Spencer, N. D.; Wieland, M.; Keller, B.; Sigrist, H. Immobilization of the Cell-Adhesive Peptide Arg-Gly-Asp-Cys (RGDC) on Titanium Surfaces by Covalent Chemical Attachment. J. Mater. Sci.: Mater. Med. 1997, 8 (12), $867-872$.

(52) Woods, A.; Couchman, J. R.; Johansson, S.; Höök, M. Adhesion and Cytoskeletal Organisation of Fibroblasts in Response to Fibronectin Fragments. EMBO J. 1986, 5 (4), 665-670.

(53) Kim, J.-H.; Park, S.-O.; Jang, H.-J.; Jang, J.-H. Importance of the Heparin-Binding Domain of Fibronectin for Enhancing Cell Adhesion Activity of the Recombinant Fibronectin. Biotechnol. Lett. 2006, 28 (17), 1409-1413.

(54) Dalton, B. A.; McFarland, C. D.; Underwood, P. A.; Steele, J. G. Role of the Heparin Binding Domain of Fibronectin in Attachment and Spreading of Human Bone-Derived Cells. J. Cell Sci. 1995, 108 (5), 2083-2092.

(55) Bloom, L.; Ingham, K. C.; Hynes, R. O. Fibronectin Regulates Assembly of Actin Filaments and Focal Contacts in Cultured Cells via the Heparin-Binding Site in Repeat III13. Mol. Biol. Cell 1999, 10 (5), 1521-1536.

(56) Yoneda, J.; Saiki, I.; Igarashi, Y.; Kobayashi, H.; Fujii, H.; Ishizaki, Y.; Kimizuka, F.; Kato, I.; Azuma, I. Role of the Heparin-Binding Domain of Chimeric Peptides Derived from Fibronectin in Cell Spreading and Motility. Exp. Cell Res. 1995, 217 (1), 169179.

(57) Kang, W.; Park, S.; Jang, J.-H. Kinetic and Functional Analysis of the Heparin- 
Binding Domain of Fibronectin. Biotechnol. Lett. 2008, 30 (1), 55-59.

(58) Schwartz, M. A.; Assoian, R. K. Integrins and Cell Proliferation: Regulation of CyclinDependent Kinases via Cytoplasmic Signaling Pathways. J. Cell Sci. 2001, 114 (14), 2553-2560.

(59) Baron, V.; Schwartz, M. Cell Adhesion Regulates Ubiquitin-Mediated Degradation of the Platelet-Derived Growth Factor Receptor Beta. J. Biol. Chem. 2000, 275 (50), $39318-39323$.

(60) Moro, L. Integrins Induce Activation of EGF Receptor: Role in MAP Kinase Induction and Adhesion-Dependent Cell Survival. EMBO J. 1998, 17 (22), 6622-6632.

(61) García, A. J.; Reyes, C. D. Bio-Adhesive Surfaces to Promote Osteoblast Differentiation and Bone Formation. J. Dent. Res. 2005, 84, 407.

(62) Hughes, D. E.; Salter, D. M.; Dedhar, S.; Simpson, R. Integrin Expression in Human Bone. J. Bone Miner. Res. 1993, 8 (5), 527-533.

(63) Grzesik, W. J.; Robey, P. G. Bone Matrix RGD Glycoproteins: Immunolocalization and Interaction with Human Primary Osteoblastic Bone Cells in Vitro. J. Bone Miner. Res. 1994, 9 (4), 487-496. 


\section{TABLES}

Table 1. QCM-D study of the thickness and surface mass density of the bound biomolecules to silanized Ti sensors calculated using the Voigt model.

\begin{tabular}{|l|c|c|}
\hline Biomolecules & Thickness $(\mathbf{n m})$ & Surface mass density $\left(\mathbf{n g} / \mathbf{c m}^{\mathbf{2}}\right)$ \\
\hline CAS & $5,54( \pm 0,09)$ & $609,14( \pm 10,19)$ \\
\hline HBII & $7,49( \pm 0,13)$ & $823,80( \pm 14,00)$ \\
\hline linRGD & $2,00( \pm 0,17)$ & $220,12( \pm 9,17)$ \\
\hline CRGD & $1,82( \pm 0,14)$ & $200,01( \pm 14,98)$ \\
\hline
\end{tabular}

Table 2. Surface chemical composition (expressed as atomic percentages) of the biofunctionalized samples by XPS.

\begin{tabular}{lrrrrr} 
& \multicolumn{2}{c}{ N 1s } & O 1s & Si 2p & \multicolumn{1}{c}{ Ti 2p } \\
\cline { 2 - 6 } & & & & & \\
\hline Ctrol & $22,96( \pm 1.87)$ & $0,76( \pm 0.19)$ & $56,25( \pm 1.45)$ & $0,49( \pm 0.08)$ & $19,57( \pm 0.15)$ \\
CAS & $47,63( \pm 0.13)$ & $10,57( \pm 0.25)$ & $31,93( \pm 0.04)$ & $3,01( \pm 0.06)$ & $6,87( \pm 0.23)$ \\
HBII & $46,45( \pm 1.48)$ & $10,26( \pm 0.53)$ & $32,85( \pm 1.22)$ & $3,66( \pm 0.08)$ & $6,78( \pm 0.72)$ \\
linRGD & $32,16( \pm 0.42)$ & $4,82( \pm 0.03)$ & $46,31( \pm 0.33)$ & $4,82( \pm 0.33)$ & $11,91( \pm 0.28)$ \\
cRGD & $34,77( \pm 1.07)$ & $5,33( \pm 0.05)$ & $43,55( \pm 0.76)$ & $5,53( \pm 0.04)$ & $10,83( \pm 0.30)$
\end{tabular}




\section{FIGURE CAPTIONS}

Fig. 1. Adhesion of rMSCs onto Ti25Nb21Hf alloy biofunctionalized with the different biomolecules after $4 \mathrm{~h}$ of culture. Letter "a" indicates study groups with no statistical differences with FN. Letter " $b$ " indicates study groups with statistically significant differences compared to FN.

Fig. 2. Spreading of rMSCs onto Ti25Nb21Hf alloy biofunctionalized with the different biomolecules after $4 \mathrm{~h}$ of culture. Letter "a" indicates study groups with no statistical differences with FN. Letter "b" indicates study groups with statistically significant differences compared to FN.

Fig. 3. Representative high magnification images (60x) of rMSCs spreading and morphology after $4 \mathrm{~h}$ in culture with FN (A), linRGD (B), cRGD (C), CAS (D), HB II (E), CAS-HBII 30:70 (F), CAS-HBII 50:50 (G) and CAS-HBII (H) biofunctionalized surfaces. Scale bar 20 $\mu \mathrm{m}$.

Fig. 4. Proliferation of rMSCs onto Ti25Nb21Hf alloy biofunctionalized with the different biomolecules. At each time, "a", "c", "g" and "k" indicates no statistical differences compared to FN while distinct letters denote statistical differences to $\mathrm{FN}$ and between conditions.

Fig. 5. ALP activity of rMSCs onto Ti25Nb21Hf alloy biofunctionalized with the different biomolecules. At each time, "a", "c" and "e" indicates no statistical differences compared to FN while distinct letters denote statistical differences to FN and between conditions.

Fig. 6. Summary of cell responses to functionalized surfaces with FN, different mixtures of CAS and HBII fragments (30:70, 50:50 and 70:30) and CAS and HBII fragments alone. Biomolecules with similar responses were grouped by colors for better interpretation of results. 


\section{TABLE OF CONTENTS (TOC)}

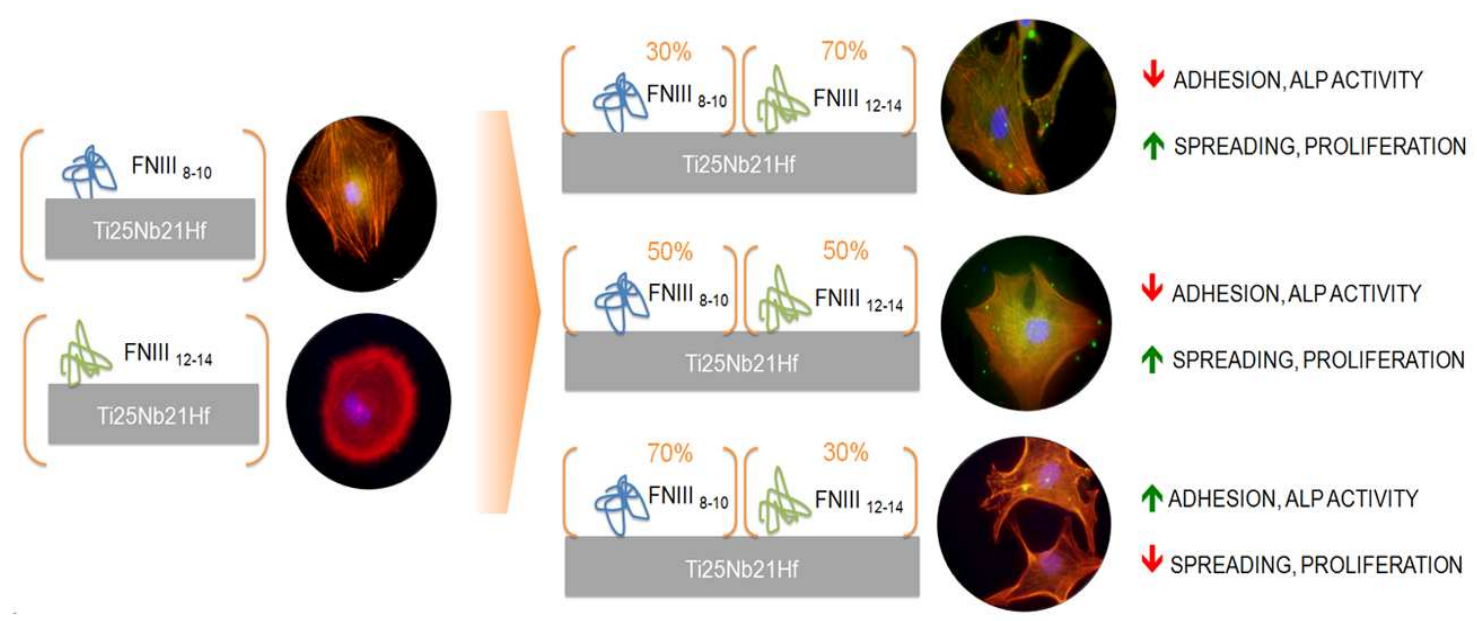

1

2

5

6

7

8

9

10

11

12

13

14

15

16

17

18

19

20

21

22

23

24

25

26

27

28

29

30

31

32

33

34

35

36

37

38

39

40

41

42

43

44

45

46

47

48

49

50

51

52

53

54

55

56

57

58

59

60 
Fig. 1. Adhesion of rMSCs onto Ti25Nb21Hf alloy biofunctionalized with the different biomolecules after $4 \mathrm{~h}$ of culture. Letter " $a$ " indicates study groups with no statistical differences with FN. Letter " $b$ " indicates study groups with statistically significant differences compared to FN. $68 \times 55 \mathrm{~mm}(300 \times 300 \mathrm{DPI})$ 


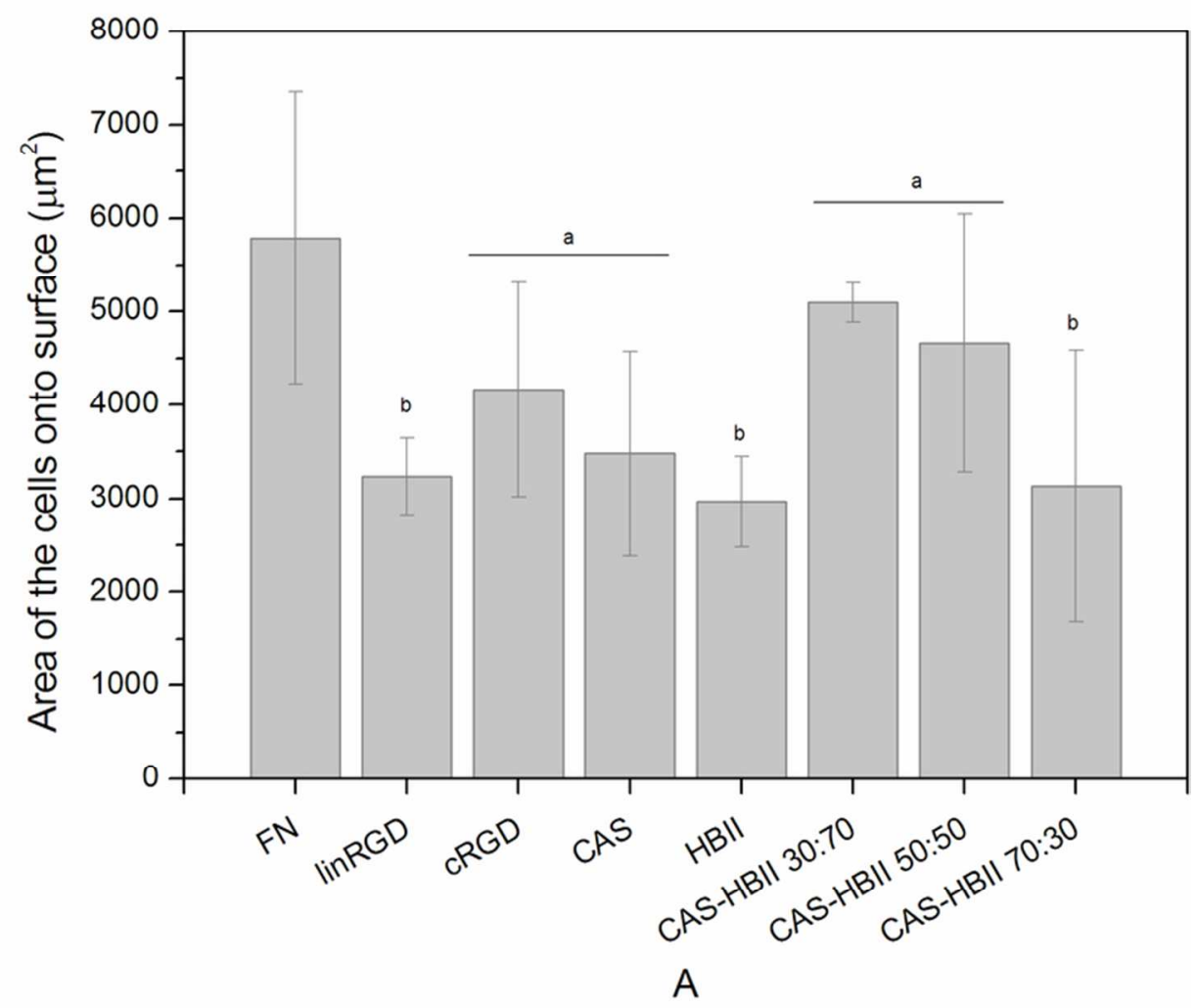

Fig. 2. Spreading of rMSCs onto Ti25Nb21Hf alloy biofunctionalized with the different biomolecules after $4 \mathrm{~h}$ of culture. Letter "a" indicates study groups with no statistical differences with FN. Letter " $b$ " indicates study groups with statistically significant differences compared to FN. $73 \times 63 \mathrm{~mm}(300 \times 300$ DPI) 

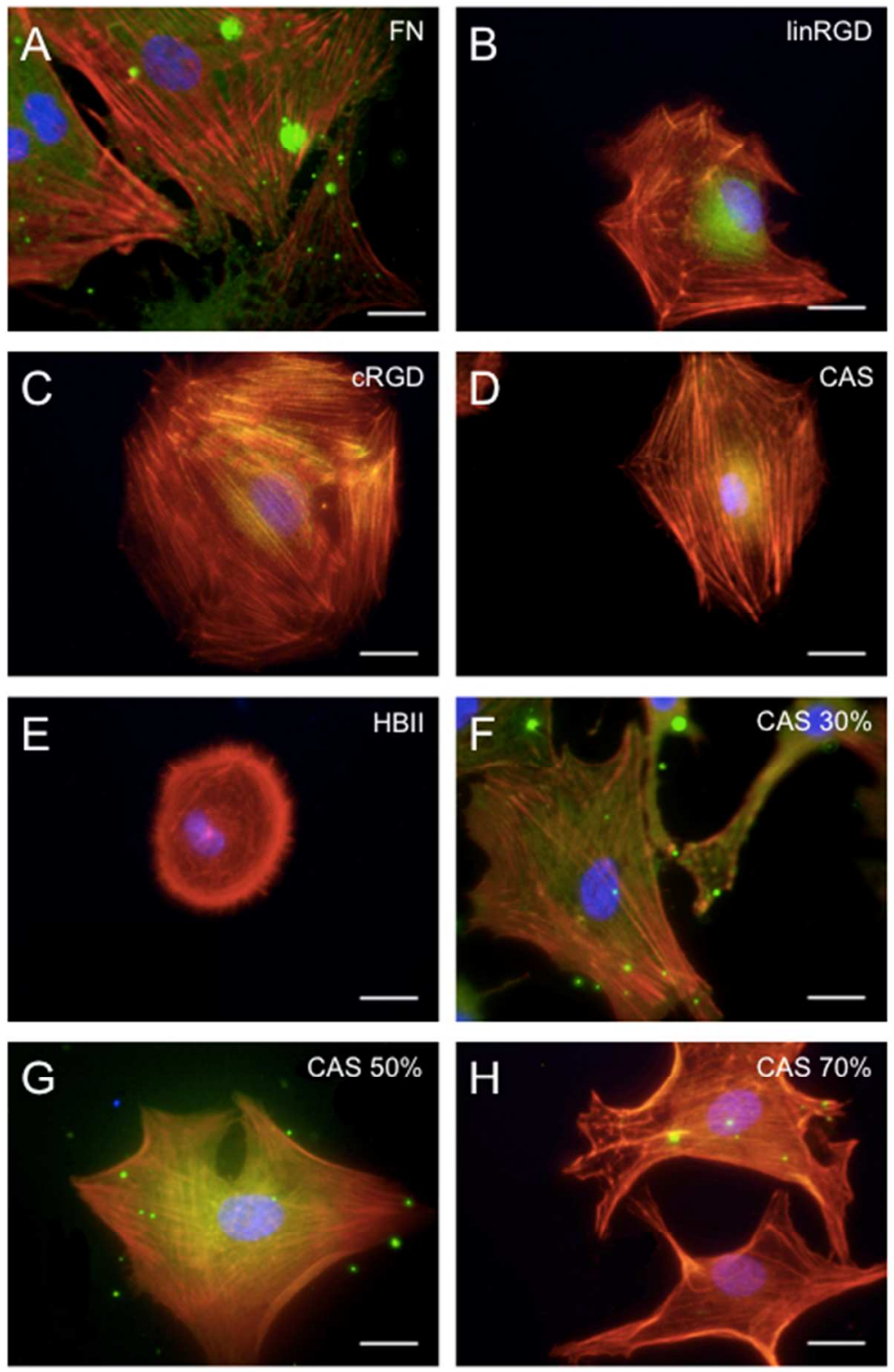

Fig. 3. Representative high magnification images (60x) of rMSCs spreading and morphology after $4 \mathrm{~h}$ in culture with FN (A), linRGD (B), cRGD (C), CAS (D), HB II (E), CAS-HBII 30:70 (F), CAS-HBII 50:50 (G) and CAS-HBII $(\mathrm{H})$ biofunctionalized surfaces. Scale bar $20 \mu \mathrm{m}$. $42 \times 65 \mathrm{~mm}(300 \times 300 \mathrm{DPI})$ 
Fig. 4. Proliferation of rMSCs onto Ti25Nb21Hf alloy biofunctionalized with the different biomolecules. At each time, "a", " $c$ ", " $g$ " and " $k$ " indicates no statistical differences compared to FN while distinct letters denote statistical differences to FN and between conditions.

$58 \times 40 \mathrm{~mm}(300 \times 300 \mathrm{DPI})$ 
Fig. 5. ALP activity of rMSCs onto Ti25Nb21Hf alloy biofunctionalized with the different biomolecules. At each time, "a", " $c$ " and " $e$ " indicates no statistical differences compared to FN while distinct letters denote statistical differences to $\mathrm{FN}$ and between conditions. $59 \times 42 \mathrm{~mm}(300 \times 300 \mathrm{DPI})$ 
Fig. 6. Summary of cell responses to functionalized surfaces with FN, different mixtures of CAS and HBII fragments (30:70, 50:50 and 70:30) and CAS and HBII fragments alone. Biomolecules with similar responses were grouped by colors for better interpretation of results.

\section{$84 \times 40 \mathrm{~mm}(300 \times 300 \mathrm{DPI})$}




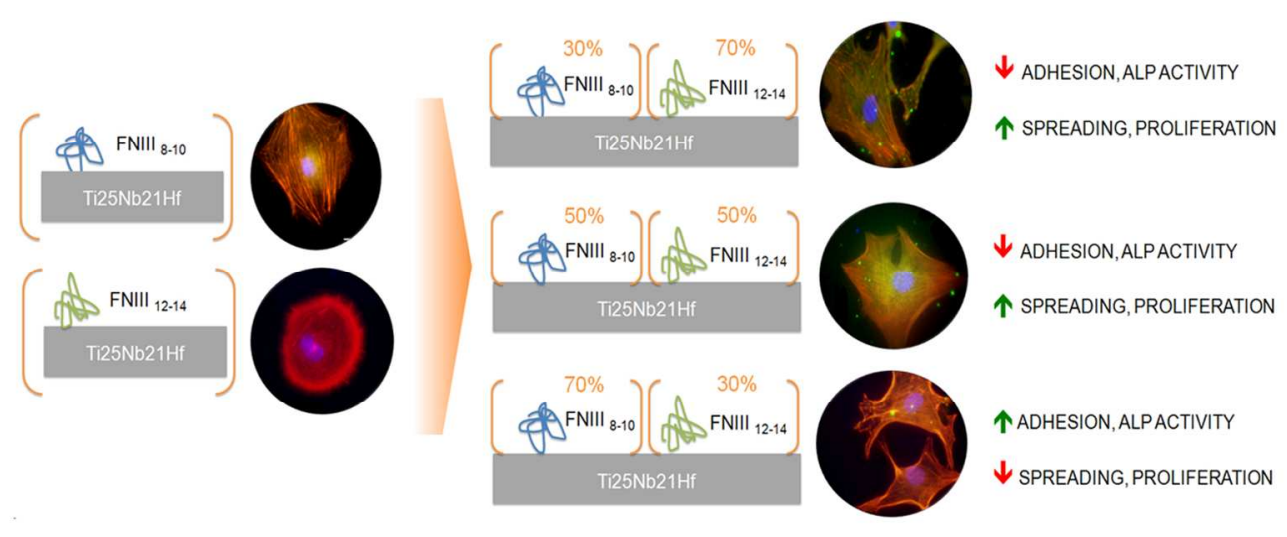

Table of Contents (TOC) $112 \times 44 \mathrm{~mm}(300 \times 300 \mathrm{DPI})$ 